
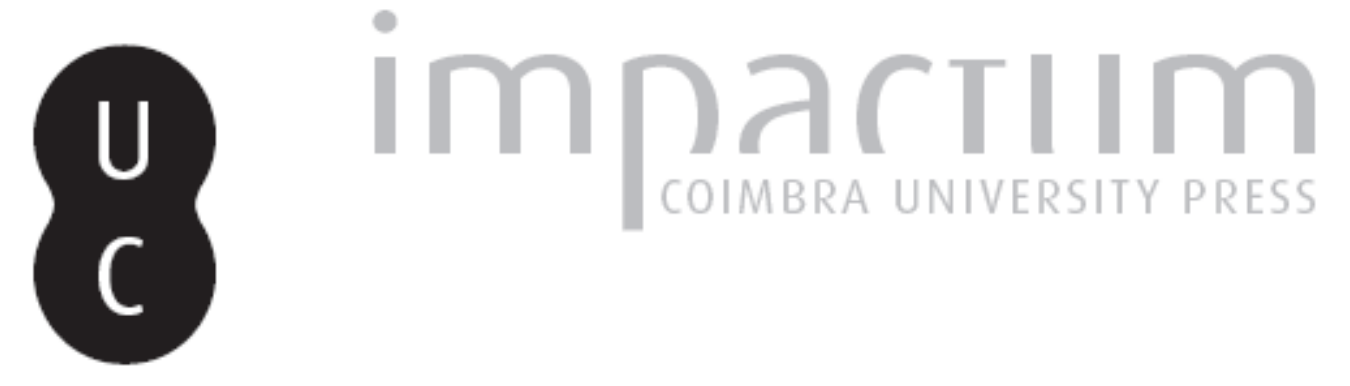

\title{
Platão: Cartas: Carta III
}

\section{Autor(es): $\quad$ Lopes, Rodolfo; Cornelli, Gabriele}

Publicado por: Imprensa da Universidade de Coimbra

URL persistente:

URl:http://hdl.handle.net/10316.2/42801

DOI:

DOI:https://doi.org/10.14195/1984-249X_21_9

Accessed : $\quad$ 26-Apr-2023 11:10:30

A navegação consulta e descarregamento dos títulos inseridos nas Bibliotecas Digitais UC Digitalis, UC Pombalina e UC Impactum, pressupõem a aceitação plena e sem reservas dos Termos e Condições de Uso destas Bibliotecas Digitais, disponíveis em https://digitalis.uc.pt/pt-pt/termos.

Conforme exposto nos referidos Termos e Condições de Uso, o descarregamento de títulos de acesso restrito requer uma licença válida de autorização devendo o utilizador aceder ao(s) documento(s) a partir de um endereço de IP da instituição detentora da supramencionada licença.

Ao utilizador é apenas permitido o descarregamento para uso pessoal, pelo que o emprego do(s) título(s) descarregado(s) para outro fim, designadamente comercial, carece de autorização do respetivo autor ou editor da obra.

Na medida em que todas as obras da UC Digitalis se encontram protegidas pelo Código do Direito de Autor e Direitos Conexos e demais legislação aplicável, toda a cópia, parcial ou total, deste documento, nos casos em que é legalmente admitida, deverá conter ou fazer-se acompanhar por este aviso.

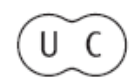




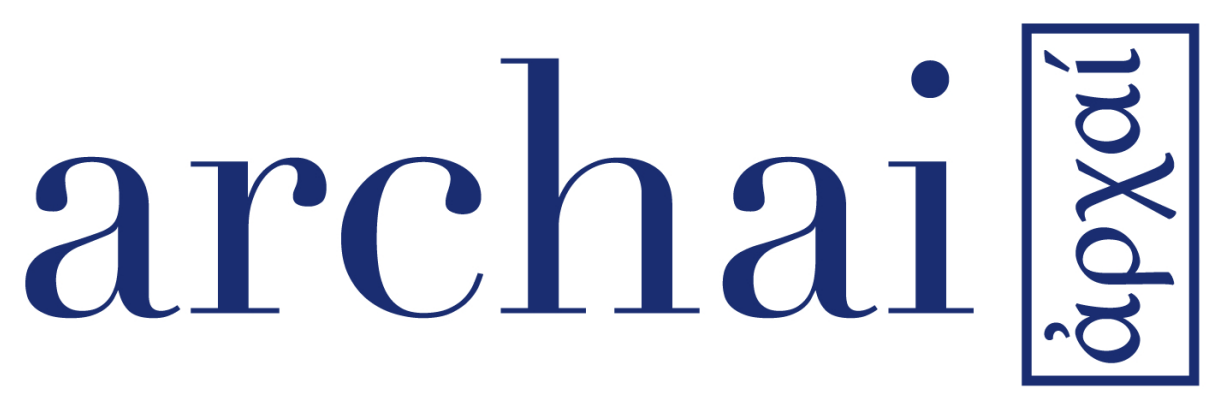

Revista sobre as origens do pensamento ocidental Journal on the Origins of Western Thought

21 | sep.-dec. 2017 
Rodolfo Lopes - Universidade de Brasília (Brasil)

rodolfolopes@unb.br

Gabriele Cornelli - Universidade de Brasília (Brasil) cornelli@unb.br

\section{Platão. Cartas: Carta III}

\section{Plato. Letters: Letter III}

LOPES, R.; CORNELlI, G. (2017). Platão. Cartas: Carta III. Archai, n. ${ }^{\circ} 21$, sep.-dec., p. 283-294

DOI: https://doi.org/10.14195/1984-249X_21_9

Palavras-chave: Platão, Cartas, Carta III, Dionísio II de Siracusa Keywords: Plato, Letters, Letter III, Dionysus II of Siracuse

A presente tradução é parte de um projeto conjunto dos autores, que consiste em verter para o Português todas as cartas tradicionalmente incluídas no corpus Platonicum. A ideia foi germinada na pesquisa que temos desenvolvido na Cátedra UNESCO Archai e, por isso mesmo, é materializada na revista que lhe pertence. Nesta primeira fase do projeto, estão sendo publicadas traduções preliminares de cada carta, acompanhadas de breves parágrafos introdutórios sobre o seu contexto. 


\section{archai圈}

no 21, sep.-dec. 2017

Rodolfo Lopes, Gabriele Cornelli, 'Platão. Cartas: Carta III, p. 283-294
Como decerto será do conhecimento comum, esta secção epistolar do corpus tem sérios problemas quanto à sua autoria. Na verdade, no total de 13 cartas, apenas duas delas podem ser atribuídas a Platão; ainda que essa pretensão de autenticidade esteja longe de alcançar um consenso entre os autores. São elas (1) a famosa Carta VII, que ainda hoje divide a comunidade de platonistas entre aqueles que a aceitam como autêntica e os que não ${ }^{1}$; e (2) a Carta VIII, que tem menos condições de ser atribuída a Platão, dado o elevado número de anacronismos que apresenta (cf. Brisson, 2008, p. 623). Todas as outras são inquestionavelmente espúrias.

Em todo o caso, o problema da autenticidade é minimizado pelo interesse que tal repositório epistolar tem suscitado ao longo de tantos séculos de exegese platonista. O conjunto das 13 cartas está incluído no corpus já desde as suas antiquíssimas divisões: nas trilogias de Aristófanes de Bizâncio e também nas clássicas tetralogias tradicionalmente atribuídas a Trasilo (vide Lopes, 2013). Em ambos os modelos as cartas ocupam a última posição (depois de Críton e Fédon em Aristófanes; depois de Minos, Leis e Epinomis em Trasilo). Isso não implica, todavia, que os antigos considerassem as cartas espúrias; pelo contrário, aliás, visto que generalidade dos autores (pagãos e cristãos) as toma por autênticas (vide Zaragoza \& Gómez cardó, 1992, p. 429-433). São de notar as possíveis exceções de Proclo e Aristóteles. O primeiro, segundo um testimonium de Olimpiodoro, teria rejeitado a totalidade das cartas; mas tal

1 Veja-se neste sentido a recente publicação de Burnyeat, M.; Frede, M. (2015). 
relato acabou por ser desconsiderado, pois na rejeição estavam também incluídas as Leis e a República (vide Maddalena, 1948, p. V). Quanto ao segundo, não se pode falar de rejeição, mas apenas de silêncio: Aristóteles nunca refere as cartas de Platão, nem mesmo quando, no Livro V da Política, fala da querela entre Díon e Dionísio de Siracusa. Alguns dos autores que defendem a inautenticidade da Carta VII usam este silêncio de Aristóteles como argumento.

Nos manuscritos medievais as cartas aparecem listadas no final, logo antes dos diálogos considerados espúrios. Esta posição não deve indiciar suspeitas de autenticidade, visto em apenas alguns deles apenas a Carta XII surge notada como espúria.

Assim, a tendência de rejeitar a autoria platónica das cartas é bastante recente, tendo em conta a longa tradição de comentário e interpretação; mais precisamente a partir de inícios do século XIX, depois dos trabalhos de Meiners (1782), Ast (1816) e Karsten (1864), que as reconhecem todas como espúrias.

\section{SObre A CARTA III}

O contexto desta carta é o regresso da (suposta) terceira viagem de Platão à Sicília. Regressado a Atenas, escreve a Dionísio II com a finalidade de se defender de duas calúnias que este contra si levantara. Ambas dizem respeito a um mau aconselhamento político por parte de Platão: (1) não reestabelecer as colónias gregas em Siracusa destruídas pelos bárbaros; (2) não substituir a tirania por uma monarquia. O sujeito da carta tenta rebater ambas as acusações, dizendo que o seu aconselhamento foi no sentido

\section{archai圈}

no 21, sep.-dec. 2017

Rodolfo Lopes, Gabriele Cornelli, 'Platão. Cartas: Carta III, p. 283-294 


\section{archai 䀥}

no 21 , sep.-dec. 2017

Rodolfo Lopes, Gabriele Cornelli, 'Platão. Cartas: Carta III, p. 283-294 oposto, sugerindo assim que Dionísio II o estaria utilizando como desculpa para as suas más decisões.

Um outro aspecto em destaque é a acusação de Platão de que Dionísio II teria violado o acordo que haviam feito a propósito do desterro de Díon. Ao contrário do que ficara estabelecido (restituição dos bens e manutenção da renda anual), Dionísio II vendeu todas as posses de Díon. O tom da carta é, pois, de um profundo ressentimento perante as atitudes do tirano, acusado de mentir, faltar ao prometido e, sobretudo, de ter ficado obcecado pela riqueza e pelo poder.

\section{Platão a Dionísio}

(315a) Se me dirigir a ti com 'Platão felicita Dionísio', (315b) acaso terei acertado na melhor forma de saudação? Ou será melhor seguir o meu hábito de escrever 'que tudo esteja bem', como costumo fazer nas cartas que envio aos amigos? É que tu mesmo, conforme disseram os que assistiram, te dirigiste assim ao deus em Delfos, elogiando-o com esta frase, que, segundo dizem, deixaste escrita:

\section{“Felicita E MANTÉM FELIZ A VidA do TiRANO"}

(315c) Quanto a mim, nem a um homem faria tal apelo; menos ainda a um deus. Não faria isso com um deus, porque estaria impondo algo contra a natureza divina, a qual se situa além do prazer e da dor. Não o faria com um homem, porque em muitos casos o prazer e a dor geram um dano, pois criam na alma incapacidade de aprender, esquecimento, estupidez e insolência. Isto é o que tenho a dizer 
acerca da forma de saudação. Quanto a ti, depois de leres, escolhe como prefiras.

Não pouca gente comenta que tu dizes a alguns dos que te foram enviados como (315d) embaixadores que, tendo-te eu ouvido falar, em dado momento, que estavas para estabelecer cidades gregas na Sicília e para aliviar a carga dos Siracusanos, mudando a tirania para um regime de monarquia hereditária, te impedi de fazê-lo nessa ocasião, apesar do teu extremo empenho, segundo tu dizes; que eu agora terei instruído Díon a colocar em prática esse plano; e que nós te retirámos (315e) o poder com as tuas próprias ideias. Tu lá saberás se tiras algum benefício destas afirmações, mas a verdade é que estás sendo injusto comigo ao dizeres o contrário do que aconteceu. Já me basta ter sido injuriado por Filistides (e por muitos outros) diante dos mercenários e perante uma multidão de Siracusanos por ter permanecido na acrópole; e, aos olhos dos de fora, se algum problema vem a acontecer, tudo me é imputado, pois dizem que tu me seguias em tudo. Mas tu sabes perfeitamente (316a) que, dos assuntos políticos com que lidei aliado a ti, poucos aceitei de bom grado (no início, quando acreditava que poderia fazer alguma coisa importante). Tratava-se de coisas relativamente insignificantes, como proémios a leis; independentemente do que tu ou algum outro acrescentou depois. Ouvi dizer que alguns de vocês lhes fizeram revisões, mas é claro que cada um desses textos pode ser avaliado de acordo com o meu carácter. Por isso, conforme acabei de explicitar, não preciso de ser caluniado perante os Siracusanos ou quaisquer outros que acreditem naquilo que dizes. Preciso sim (e muito)

\section{archai莀}

no 21, sep.-dec. 2017

Rodolfo Lopes, Gabriele Cornelli, 'Platão. Cartas: Carta III, p. 283-294 


\section{archai圈}

no 21, sep.-dec. 2017

Rodolfo Lopes, Gabriele Cornelli, 'Platão. Cartas: Carta III, p. 283-294 da defesa (316b) perante essa calúnia que me foi lançada anteriormente e esta outra, maior e mais grave, que agora foi produzida. É necessário que eu produza uma dupla defesa perante estas duas calúnias: primeiro, que foi prudente ter evitado colaborar contigo na administração da cidade; segundo, que não foi meu esse parecer nem essa reserva que, segundo dizes, eu lancei como obstáculo à tua intenção de estabelecer as cidades Gregas (316c).

Para começar, presta atenção ao que te digo em relação ao primeiro ponto. Eu vim para Siracusa, porque fui convidado por ti e por Díon, que eu conheço bem e com quem, desde há muito, mantenho laços de hospitalidade. Ele estava numa fase madura e estável, que, com certeza, é indispensável a quem tem juízo e o mínimo de responsabilidade para deliberar sobre questões como as que tu tinhas em mãos. Mas tu eras ainda demasiado jovem, inexperiente em assuntos (316d) acerca dos quais deverias ter experiência; e eras para mim totalmente desconhecido. Depois disso, talvez um homem, um deus, ou talvez o acaso levou Díon para longe de ti, e ficaste sozinho. Achas que naquele momento eu poderia aliar-me politicamente contigo, quando tinha perdido o meu aliado sensato e via o insensato rendido a uma multidão de homens vis, sem governar, mas julgando que governava, pois era governado por esse tipo de gente? O que poderia eu fazer perante tal coisa? Não fiz senão aquilo que estava obrigado a fazer: abandonar (316e) a política, precaver-me das calúnias dos invejosos, e, acima de tudo, por mais que estivessem separados e em divergência, tentar manter-vos amigos, tanto quanto eu pudesse. Disto até tu és testemunha, de que jamais desisti de 
cumprir este objetivo. A custo concordámos que eu embarcaria (317a) para a minha terra, visto que a vossa estava em guerra; e, logo que chegasse a paz, eu e Díon regressaríamos, quando nos chamasses. Foi assim que aconteceu aquando da minha primeira viagem a Siracusa e do meu regresso a casa, são e salvo. Na segunda, quando se estabeleceu a paz, convidaste-me, mas não conforme o combinado: mandaste-me chegar sozinho, dizendo que Díon viria depois. Foi por isso que não compareci e, assim, desagradei também a Díon; pois ele achava (317b) que era melhor que eu fosse e me colocasse à tua disposição. Depois disto, passado um ano, chegou uma trirreme e uma carta tua, a qual começava por dizer que, caso eu viesse, todas as questões acerca de Díon se resolveriam de acordo com a minha vontade, e que seria o contrário, caso ele não viesse. Envergonha-me dizer quantas cartas chegaram (317c) da Itália e da Sicília - tuas, de outros que agiam em teu nome e de muitos companheiros e conhecidos meus. Todas elas me exortavam a partir e me persuadiam a ficar sob as tuas ordens. A opinião de todos eles, a começar por Díon, era que eu partisse sem demora. No entanto, eu recorria à minha idade como desculpa e, em relação a ti, sublinhava que não serias capaz de enfrentar os nossos detratores, que queriam tornar-se inimigos. Nessa altura eu via, como vejo também agora, que as fortunas grandes e desmedidas, tanto de cidadãos particulares quanto de monarcas, (317d) quanto maiores forem, mais alimentam detratores e companhias de prazeres vis e vergonhosos; pois não existe mal maior do que a riqueza ou qualquer outra forma de poder. Mesmo assim fui, sem que nada disto me abalasse; pois achava que nenhum dos meus amigos me deveria

\section{archai產}

no 21 , sep.-dec. 2017

Rodolfo Lopes, Gabriele Cornelli, 'Platão. Cartas: Carta III, p. 283-294 


\section{archai 䀥}

no 21 , sep.-dec. 2017

Rodolfo Lopes, Gabriele Cornelli, 'Platão. Cartas: Carta III, p. 283-294 acusar de, por minha negligência, ter destruído todos os teus bens (317e), quando me era possível não tê-los deixado a perder. Quando cheguei - e tu sabes tudo o que aconteceu a partir daqui - pedite logo que, em respeito ao acordo que tínhamos estabelecido por carta, te reconciliasses com Díon, tendo-te eu indicado os termos da reconciliação. Se me tivesses dado ouvidos, as coisas teriam corrido bem melhor do que estão agora, tanto para ti, quanto para Siracusa e para os outros gregos. Essa era a minha previsão. Em seguida, pedi-te que os bens de Díon ficassem (318a) com os seus familiares e não fossem distribuídos por entre aqueles que tu conheces. Além disto, eu achava que lhe devia ser entregue a sua renda anual, como era devido; e que, desde a minha chegada, ela fosse ainda maior em vez de inferior. Visto que nenhum destes pedidos me foi concedido, achei melhor ir embora. Depois disto, tu convenceste-me a ficar por mais um ano e prometeste devolver toda a fortuna de Díon, enviando metade para Corinto e deixando o restante com o seu filho (318b). Muita coisa eu poderia dizer sobre promessas que não cumpriste; mas, por serem tantas, faço apenas um resumo. Alienaste todos os bens de Díon sem o seu consentimento, apesar de teres dito que não venderias sem ele consentir. Assim, ilustríssimo, colocaste um vergonhoso epítome a todas as tuas promessas: congeminaste um estratagema nada elegante, requintado, justo nem conveniente; intimidaste-me, como se eu não soubesse o que estava acontecendo naquele momento, de tal forma que (318c) eu não procurasse enviar o dinheiro. $\mathrm{Na}$ época em que desterraste Heraclides, isso não me pareceu justo nem a mim nem aos Siracusanos; daí que, com o apoio de Teódoto e Euríbio, te pedi que

\section{0}


não tomasses essa medida. Consideraste esta atitude motivo suficiente para dizeres que há muito tempo era claro que eu não me preocupava contigo, mas sim com Díon e com os companheiros de Díon. Como naquele momento Heraclides e Teódoto, companheiros de Díon, estavam sendo alvo de calúnias, (318d) eu tentei a todo o custo articular para que eles não fossem punidos.

Assim foi a aliança política que existia entre mim e ti. Se notaste algum outro comportamento estranho da minha parte para contigo, faz sentido pensares que todas as coisas têm o mesmo motivo. E não te admires: qualquer pessoa de bom-senso me consideraria mau-carácter, com razão, se eu fosse seduzido pela grandeza do teu poder e traísse assim um antigo amigo e hóspede (e falo assim mesmo: em nada é inferior a ti) que caiu em desgraça por tua causa (318e), e me colocasse do teu lado, que o trataste injustamente, e obedecesse a tudo quanto tu determinasses por causa, evidentemente, das riquezas. É que nenhum outro motivo podia dar-se para a minha mudança de comportamento, se é que essa mudança existiu. Foi tudo isto (que aconteceu por tua causa) que provocou essa falsa amizade e incompatibilidade entre mim e ti.

O discurso que tem vindo a ser feito até este ponto leva-me para perto do discurso acerca do segundo assunto de que me devo defender. (319a) Presta o máximo de atenção e examina se te parece que estou dizendo alguma mentira e não falando a verdade. Afirmo que tu, quando estávamos no jardim com Arquedemo e Aristócrito, uns 20 dias antes do meu regresso de Siracusa para casa, me censuraste

\section{archai啳}

no 21 , sep.-dec. 2017

Rodolfo Lopes, Gabriele Cornelli, 'Platão. Cartas: Carta III, p. 283-294 


\section{archai 䀥}

no 21, sep.-dec. 2017

Rodolfo Lopes, Gabriele Cornelli, 'Platão. Cartas: Carta III', p. 283-294 pelas mesmas coisas de que agora falas: que eu me preocupava mais com Heraclides e todos os outros do que contigo. E, cara a cara com eles, me interrogaste se me lembrava que, desde que cheguei, te aconselhava a estabelecer (319b) as cidades gregas. Eu concedi que me lembrava e que, mesmo agora, me parecia ser a melhor opção. Devo dizer agora, Dionísio, aquilo que já tinha sido dito na época. Eu perguntei se te tinha dado aquele conselho apenas ou algum outro além dele. Tu respondeste-me, de modo assaz enfurecido e ofensivo, segundo tu achavas (por isso o que para ti era na época uma ofensa agora é realidade em vez de sonho), dizendo-me, (319c) com um sorriso assaz forçado, o seguinte (se bem me lembro): "Depois de ter estudado, aconselhasteme a fazer tudo isso ou a não fazer". Eu disse que te lembravas exatamente. Perguntaste: "Depois de ter estudado geometria ou como assim?”. Quanto a mim, não disse nada além disto, pois temia que, por um simples enunciado, se tornasse estreita a larga via que tinha para embarcar. Agora eis o porquê de ter feito todo este discurso: não me lances a calúnia de que eu não te deixei nem estabelecer as cidades Gregas (319d) destruídas pelos bárbaros nem aliviar os Siracusanos, substituindo a tirania por uma monarquia. De modo algum poderias proferir maior ignomínia em relação ao meu carácter. Além do mais, eu poderia apresentar uma refutação com argumentos ainda mais claros, se existisse algum tribunal competente, em como fui eu que aconselhei e foste tu que não quiseste tomar essas medidas. Não seria difícil justificar com clareza que isso teria sido a melhor coisa a fazer, tanto para ti (319e), quanto para todos os Siracusanos e Sicilianos. Então, meu caro, se dizes que não disseste aquilo que de facto 
disseste, a justiça está do meu lado. Se o admitires, parte do princípio que Estesícoro era um sábio e imita a sua palinódia, reposicionando o teu discurso da mentira para a verdade.

\section{Bibliografia}

AST, F. (1816). Platon's Leben und Schriften: Ein Versuch, im Leben wie in den Schriften des Platon das Wahre und Aechte vom Erdichteten und Untergeschobenen zu Scheiden, und die Zeitfolge der ächten Gespräche zu Bestimmen. Leipzig, Weidmann.

BLUCK, R. S. (1960). The Second Platonic Epistle. Phronesis, vol. 5.2, p. 140-151.

BRISSON, L. (2008) (org.). Platon. Oeuvres Complètes. Paris, Flammarion.

BURNYEAT, M.; FREDE, M. (2015). The Pseudo-Platonic Seventh Letter. SCOTT, D. (ed.), Oxford University Press, Oxford.

CORNELLI, G. (2007). Filosofia Antiga Underground: da Katábasis ao Hades à Caverna de Platão. REVER, ano 7, p.94-107

CORNELLI, G. (2011). O pitagorismo como categoria historiográfica. Coimbra, $\mathrm{CECH}$ - Universidade de Coimbra; São Paulo, Annablume.

ISNARDI-PARENTE, M. (2002). Platone. Lettere. Milano, Mondadori.

KARSTEN, H. T. (1864). Commentatio critica de Platonis quae feruntur Epistolis. Utrecht, Kemink et Filius.

\section{archai圈}

no 21, sep.-dec. 2017

Rodolfo Lopes, Gabriele Cornelli, 'Platão. Cartas: Carta III, p. 283-294 


\section{archai圈}

no 21, sep.-dec. 2017

Rodolfo Lopes, Gabriele Cornelli, 'Platão. Cartas: Carta III, p. 283-294
LOPES, R. (2013). A organização tetralógica do corpus Platonicum (3.56-62): uma revisão do problema. In: LEÃO, D.; CORNELLI, G.; PEIXOTO, M. (eds.). Dos homens e suas ideias. Estudos sobre as Vidas de Diógenes Laércio. Coimbra, IUC, p.125-138.

MADDALENA, A. (1948). Platone. Lettere. Bari, Laterza.

NOVOTNY, F. (1930). Platonis Epistulae commentariis illustratae. Brno. Filos. Fakulta.

SOUILHÉ, J. (1926). Platon. Lettres. Paris, Les Belles Lettres.

THESLEFF, H. (1965). The Pythagorean Texts of the Hellenistic Period. Åbo, Acta Academiae Aboensis.

THUCYDIDES. Historiae. Rec. brevique adn. crit instr. H. Stuart Jones. Oxford UP 1948-49 (OCT).

ZARAGOZA, J.; GÓMEZ CARDÓ, P. (1992). Platón. Diálogos VII (Dudosos, Apócrifos, Cartas). Madrid, Editorial Gredos.

Submetido em Fevereiro de 2017 e aprovado para publicação em Maio de 2017 